\title{
Variability of surface ozone with cloud coverage over Kolkata, India
}

\author{
D Ghosh ${ }^{1,2, *}$, S K Midya ${ }^{3}$, U SARKaR ${ }^{2}$ and T MukHERJEE ${ }^{3}$ \\ ${ }^{1}$ Department of Chemistry, Jadavpur University, Jadavpur, Kolkata 700 032, India. \\ ${ }^{2}$ Department of Chemical Engineering, Jadavpur University, Jadavpur, Kolkata 700 032, India. \\ ${ }^{3}$ Department of Atmospheric Sciences, Calcutta University, 92, A.P.C. Road, Kolkata 700 009, India. \\ ${ }^{*}$ Corresponding author. e-mail: debreka.ghosh@gmail.com
}

Critical analysis of experimental surface ozone data and cloud coverage is reported over Kolkata during the period January 2011 to December 2011. Significant relationship between these two parameters is observed. Analysis shows that the trend of surface ozone concentration and cloud coverage follow opposite tendency. Some exceptional observations are also reported. Apart from this, seasonal variation of surface ozone with columnar ozone concentration, $\mathrm{NO}_{2}$ and temperature is also examined in relation with cloud cover to obtain a possible explanation of this type of variation.

\section{Introduction}

Ozone plays a very important role in tropospheric chemistry. Though present in trace amounts $(\sim 0.0012 \%)$ in the atmosphere (Iqbal 1983), it influences the weather and climate of a place, thus acting as an important greenhouse gas (Kiehl et al. 1999; Rex et al. 2004). Solar ultra-violet (UV) radiation has several harmful effects on human health (Kondratyev and Varotsos 2001). The wavelength covering UV radiation (200-400 $\mathrm{nm}$ ) is subdivided into three spectral regions: UV-C (200-280 nm), UV-B (280-315 nm) and UV-A (315-400 nm) (Vanicek et al. 2000World Health Organization 2002). Of these, UV-C is completely absorbed by the stratospheric ozone. UV-B is influenced by changes in the column ozone whereas UV-A is least absorbed. Thus ozone also plays a key role in protecting the living beings on the earth by absorbing the most energetic part of the solar ultraviolet radiation (Alexandris et al. 1999; Varotsos et al. 1995). The amount of UV-B and
UV-A consequently determines the quantity of ozone that will be formed in the troposphere. The important factors influencing the ground level UV radiation are clouds, solar zenith angle, total column ozone and surface albedo (Burrows 1997; Kerr and McElroy 1995). Research has shown that cloud coverage controls the short-term variability of the UV-radiation in the mid-latitudes (Calbó et al. 2005). Nevertheless, cloudiness frequently disguises the influence of ozone changes on UV radiation and may alter the expected UV signal (Glandorf et al. 2005), in turn affecting the ground level ozone concentration. Thus clouds act as one of the most significant factors influencing solar radiation, and consequently the photolysis rate constants. The water droplets or the ice-crystals in the clouds enhance the scattering of the radiation resulting in loss or in a reduced atmosphere transmissivity (López et al. 2009). Hence cloud levels may have a daily variability of the UV levels at the surface (Ziemke et al. 1997). Broken cloud situation may also arise when ground level

Keywords. Surface ozone; cloud coverage; $\mathrm{NO}_{2}$; OMI. 


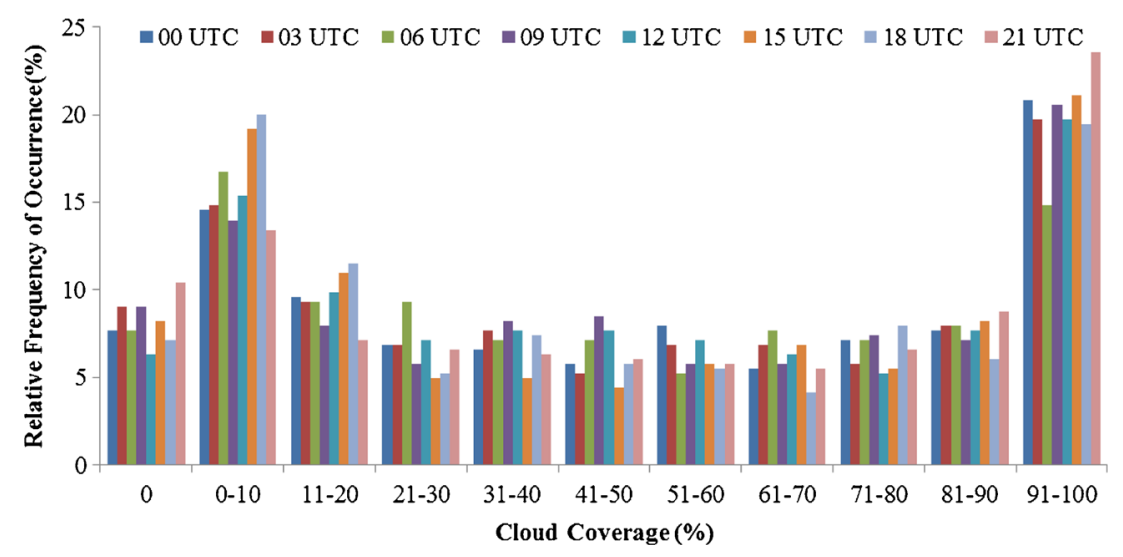

Figure 1. Percentage frequency of occurrence of cloud coverage (\%) over 24-hr of the day over Kolkata for 2011.

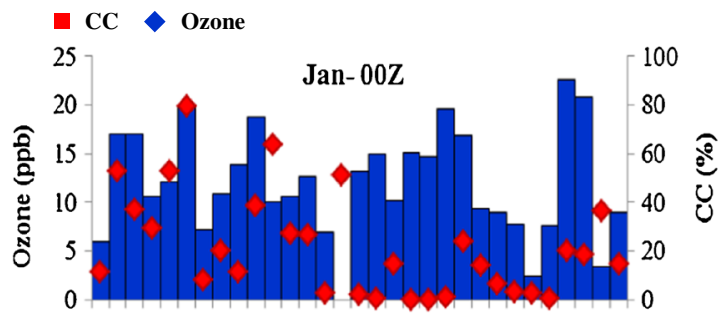

(i)

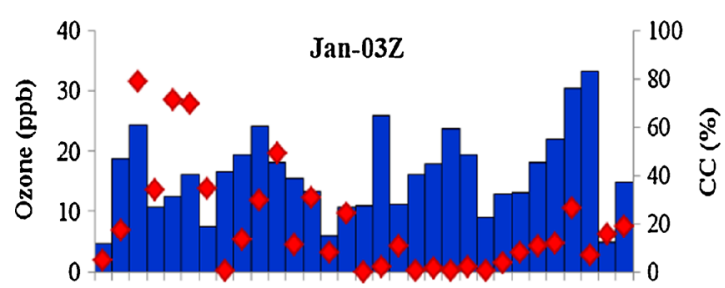

(ii)

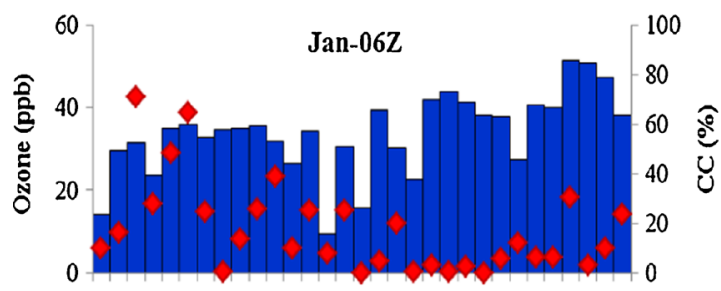

(iii)

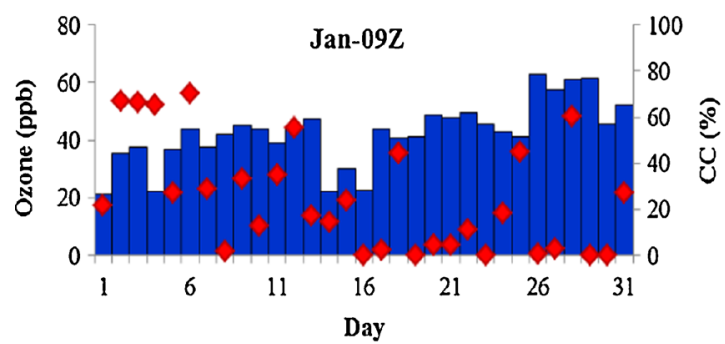

(a)

(iv)

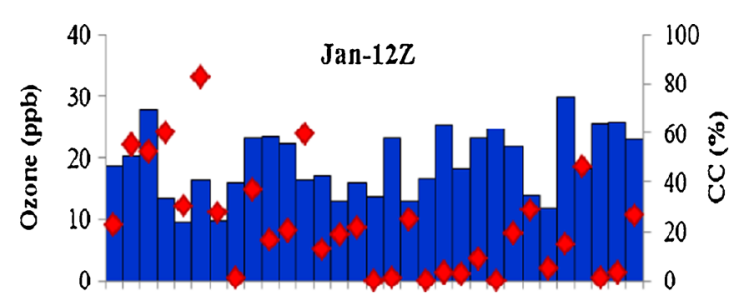

(v)



(vi)

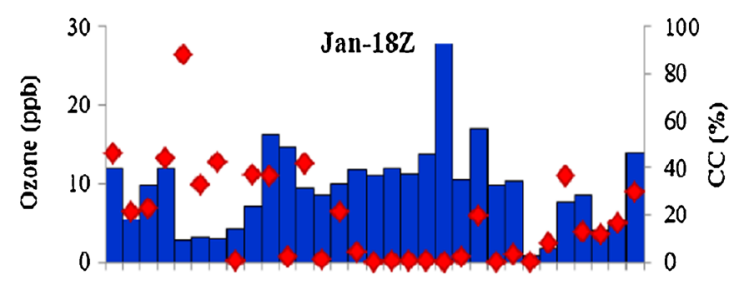

(vii)

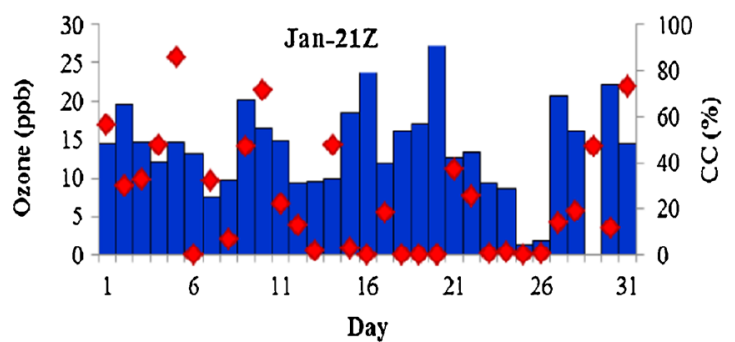

(viii)

Figure 2. (a). Monthly variation of surface ozone with cloud coverage for January 2011 at (i) 00Z, (ii) 03Z, (iii) 06Z, (iv) 09Z, (v) 12Z, (vi) 15Z, (vii) $18 \mathrm{Z}$ and (viii) $21 \mathrm{Z}$. 
radiation is found to be higher in cloudy conditions than in cloudless situations (Estupiñán et al. 1996). Due to its characteristic variability, it is difficult to predict the effects of clouds on the UV radiation. Consequently, the effect of cloud coverage is mostly taken as an approximate value and it is also location specific. In Kolkata, past studies have been conducted on the variation of total column ozone with temperature (Midya et al. 2011) and different seasons (Midya and Saha 2011). Effects of cloud coverage and total column ozone over different cities in India report that concentration of column ozone increased with the increase of cloud occurrence (Jana et al. 2010, 2011). The primary objective of this paper is to evaluate the effect of cloud coverage on the surface ozone over Kolkata.

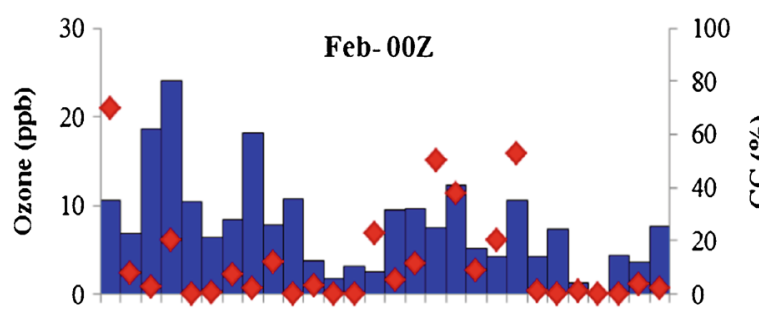

(i)



(ii)

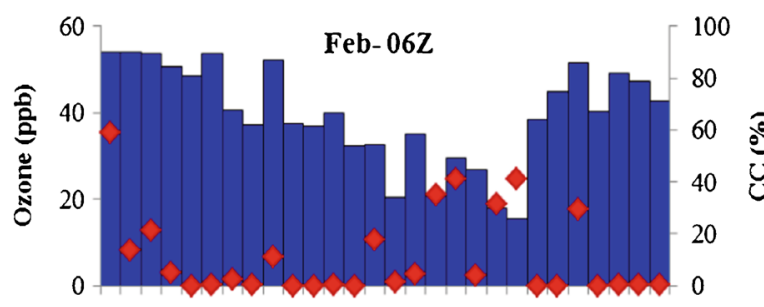

(iii)

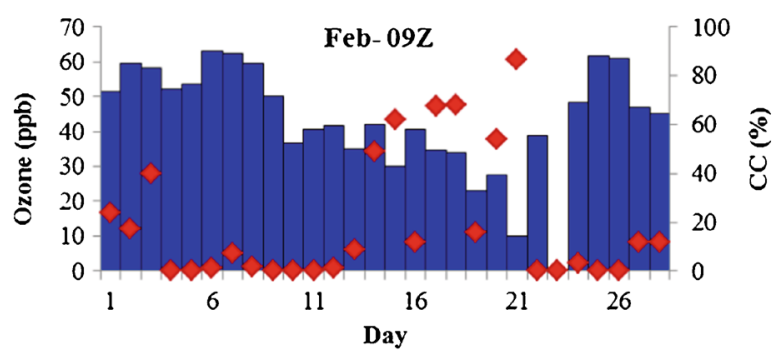

(b)

(iv)

\section{Materials and methods}

\subsection{Site description}

The experimental set-up is placed at Jadavpur University Salt Lake (JUSL) campus in the city of Kolkata $\left(22^{\circ} 33^{\prime} \mathrm{N}, 88^{\circ} 30^{\prime} \mathrm{E} ; 6 \mathrm{~m}\right.$ amsl); the second largest metropolis in south Asia. The city has a population of 4.5 million (http://www.censusindia. gov.in/2011-prov-results/prov_data_products_wb. html). The campus is situated in the greater Kolkata region in the eastern part of the city (Ghosh et al. 2013). The surrounding locality has mainly residential buildings and offices. Dhapa, the municipal solid waste landfill is located $\sim 2 \mathrm{~km}$ to the south of the site. The airport is also located $\sim 10 \mathrm{~km}$ to the north-east of the study location.

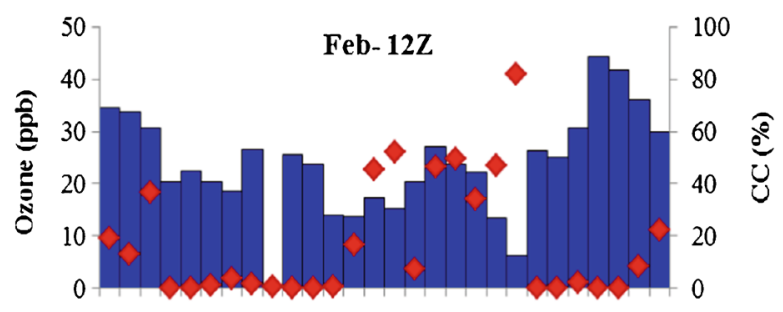

(v)



(vi)



(vii)

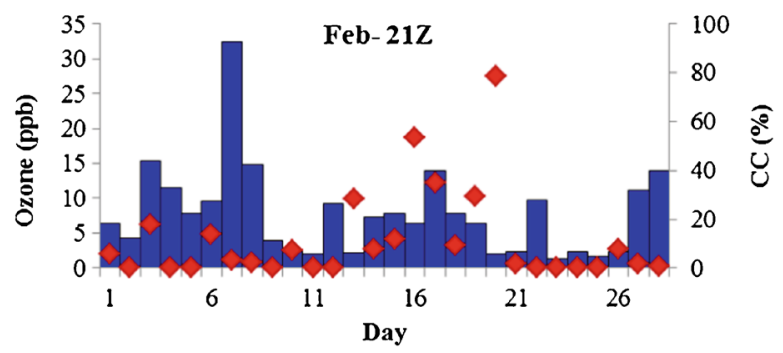

(viii)

Figure 2. (b). Monthly variation of surface ozone with cloud coverage for February 2011 at (i) 00Z, (ii) 03Z (iii) 06Z, (iv) $09 \mathrm{Z}$, (v) $12 \mathrm{Z}$, (vi) $15 \mathrm{Z}$, (vii) $18 \mathrm{Z}$ and (viii) $21 \mathrm{Z}$. 


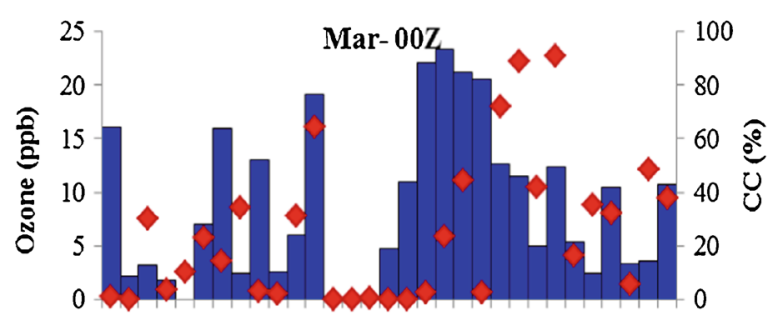

(i)

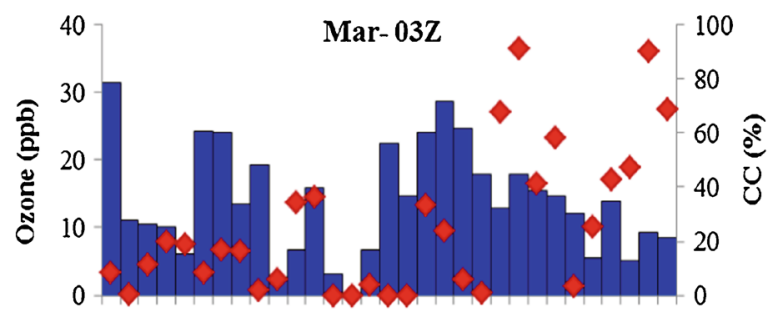

(ii)



(iii)

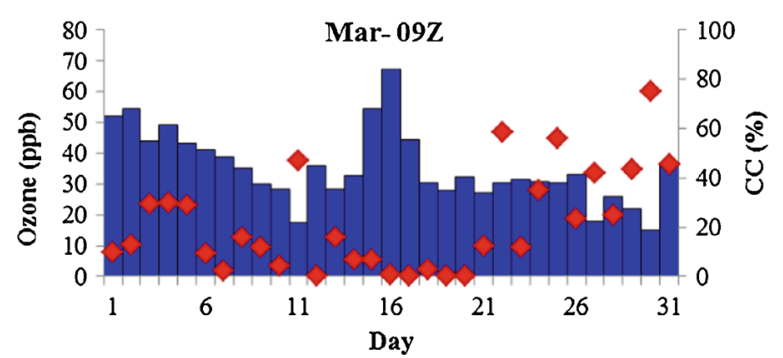

(c)

(iv)

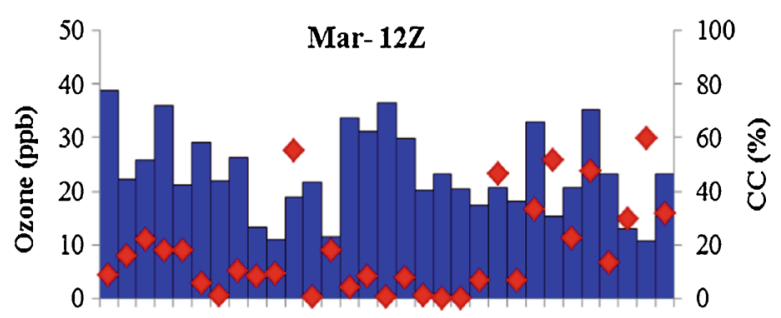

(v)

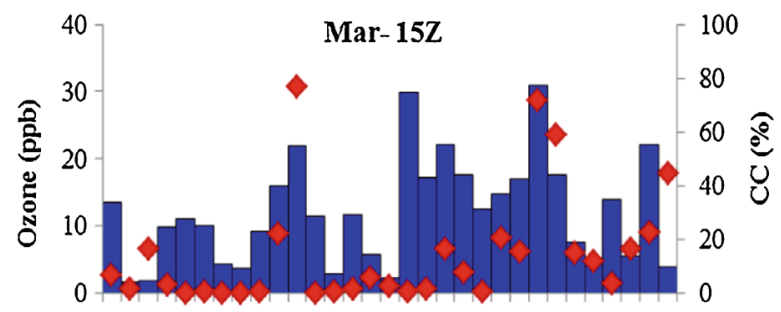

(vi)

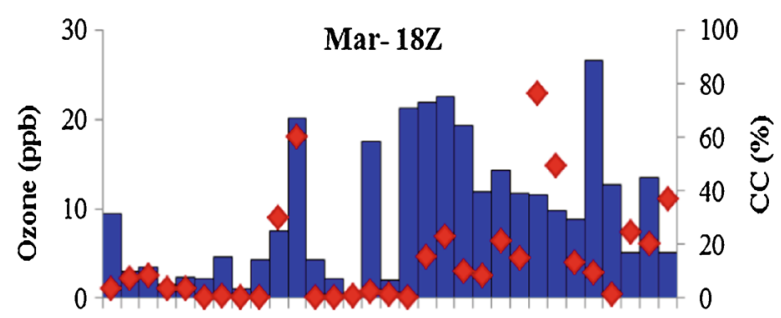

(vii)

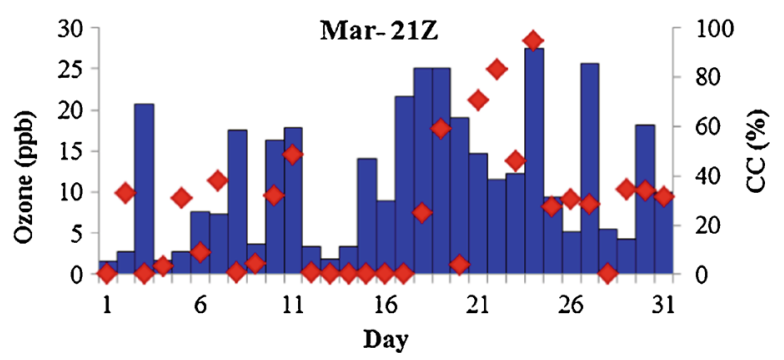

(viii)

Figure 2. (c). Monthly variation of surface ozone with cloud coverage for March 2011 at (i) 00Z, (ii) 03Z, (iii) 06Z, (iv) 09Z, (v) 12Z, (vi) 15Z, (vii) $18 \mathrm{Z}$ and (viii) $21 \mathrm{Z}$.

Several small scale industries are scattered in different parts of the city such as heavy engineering, mineral processing, pharmaceuticals, food processing, agriculture, electronics, textiles, etc. (Ghose et al. 2004). Kolkata also experiences substantial level of pollution from automobiles (Mallik et al. 2014). To the west of the city, lie two coal fired power plant stations of Budge Budge ( 30 $\mathrm{km}$ from site) and Kolaghat ( $\sim 70 \mathrm{~km}$ from site). Besides this, Haldia, the port city located about $100 \mathrm{~km}$ to the south-west of Kolkata has a major refinery and pharmaceutical company. Other industrial cities located in the vicinity of Kolkata are Durgapur and Asansol, which are situated about 170 and $210 \mathrm{~km}$ respectively to the northwest of Kolkata. They have major power plants and several industries. Thus local emissions from automobiles and the local small scale industries along with the emissions of these distant industrial regions collectively account for the overall emission scenario of the city of Kolkata.

The city experiences a tropical wet and dry climate according to Köppen climate classification. Köppen classification is an extensively used empirical climate classification system based on vegetation zones. This classification subdivides the terrestrial climate into five major climate groups, namely $\mathrm{A}, \mathrm{B}, \mathrm{C}, \mathrm{D}$, and $\mathrm{E}^{*}$, each having various types and subtypes. All these types are governed by temperature criteria except $\mathrm{B}$, which is defined by

\footnotetext{
* Gr A: Tropical/Megathermal; Gr B: Dry; Gr C: Temperate/ Mesothermal; Gr D: Continental; Gr E: Polar and Alpine.
} 


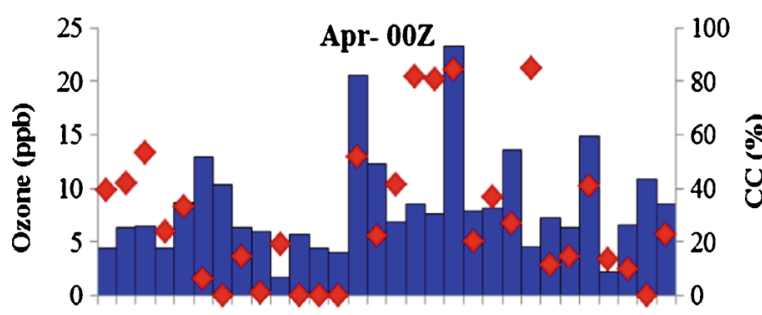

(i)

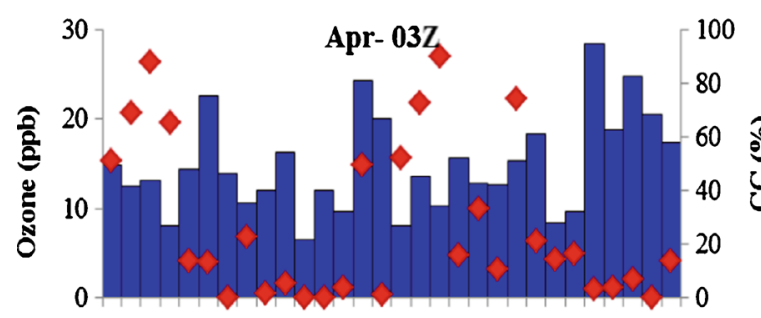

(ii)

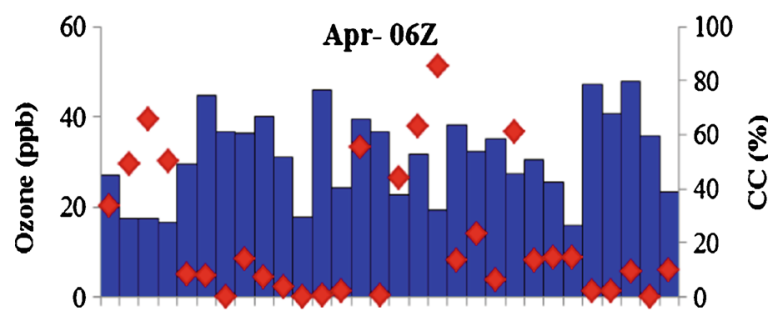

(iii)

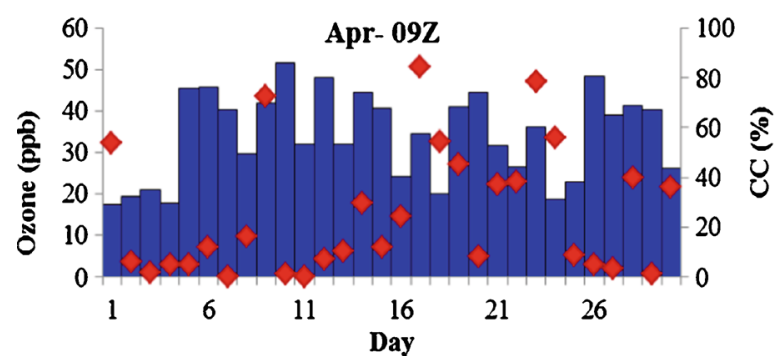

(d)

(iv)



(v)

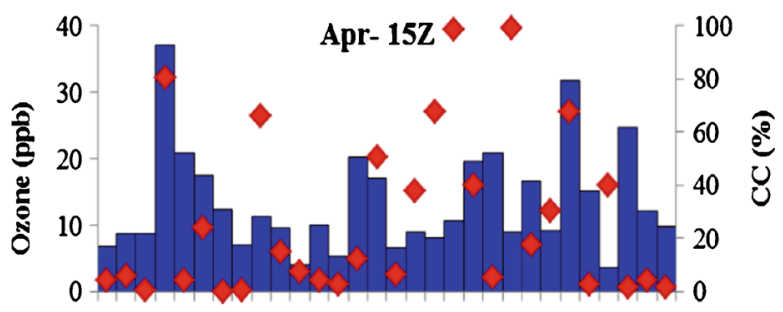

(vi)

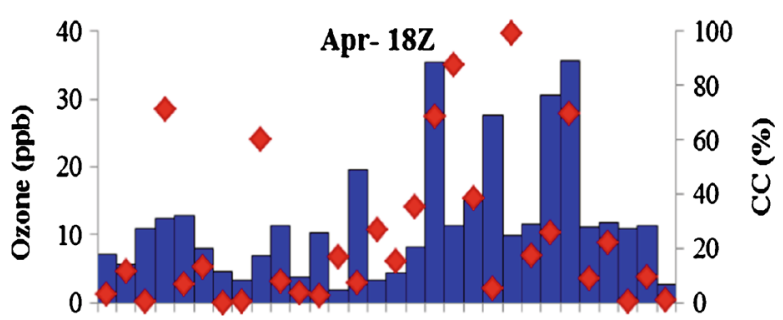

(vii)

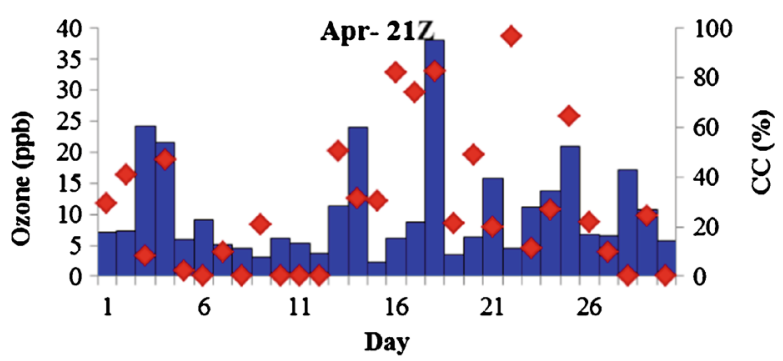

(viii)

Figure 2. (d). Monthly variation of surface ozone with cloud coverage for April 2011 at (i) 00Z, (ii) 03Z, (iii) 06Z, (iv) $09 \mathrm{Z}$, (v) 12Z, (vi) 15Z, (vii) $18 \mathrm{Z}$ and (viii) $21 \mathrm{Z}$.

dryness (http://www.britannica.com/EBchecked/ topic/322068/Koppen-climate-classification). The tropical wet-dry climate (abbreviated as Aw), as experienced in Kolkata, is characterized by distinct wet and dry seasons. Temperatures are high throughout the year and also have a wide range. Precipitation occurs mostly in the summer season. Further details of the city's meteorology are already discussed in Ghosh et al. (2013) and Mallik et al. (2014).

\subsection{Experimental set-up}

The experimental set-up consists of an ambient ozone analyzer (Model 49i; Make: Thermo Fisher Scientific, USA) installed at the study site to carry out online measurement of ambient ozone. A $4 \mathrm{~m}$ long teflon pipe connects the analyzer to the outside air through a peltier unit. The peltier unit absorbs moisture and the resultant dry air is passed through a $5 \mu \mathrm{m}$ pore size Polytetrafloroethylene (PTFE) filter paper for dust filtration after which the air enters the sample inlet of the instrument. The ozone analyzer operates on the principle that ozone molecules absorb UV light at a wavelength of $254 \mathrm{~nm}$. The degree to which the UV light is absorbed is directly related to the ozone concentration according to Beer-Lambert Law. The Model $49 i$ calculates the ozone concentration and makes the data available as analog outputs. The lower detectable limit is $1 \mathrm{ppbv}$ and the data are stored as a 15 -min average. 
The $\mathrm{NO}_{2}$ data for a complete year (2011) is collected from WBPCB.

\subsection{Satellite and meteorological data}

Along with the surface trace gas data, columnar ozone data is also collected from the NASA Giovanni Portal (disc.sci.gsfc.nasa.gov/giovanni). Columnar ozone data over Kolkata were collected from Ozone Monitoring Instrument (OMI) onboa rd the Aura satellite. This study employs the seasonal study of columnar ozone taken from OMI Level 3 with a resolution of $1.0^{\circ} \times 1.0^{\circ}$ (latitude $\times$ longitude).

The cloud coverage data is collected from the NOAA Air Resources Laboratory (ARL) website (http://ready.arl.noaa.gov/READYamet.php).



(i)

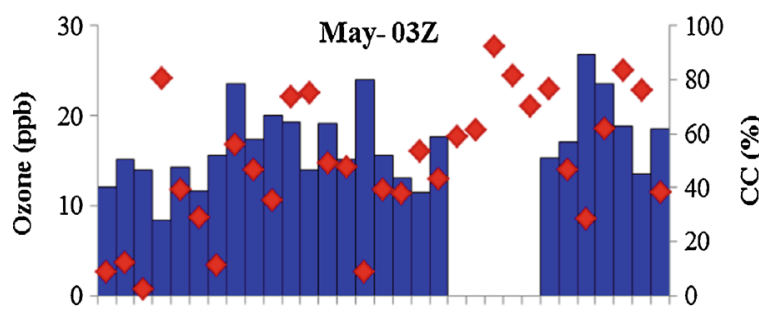

(ii)

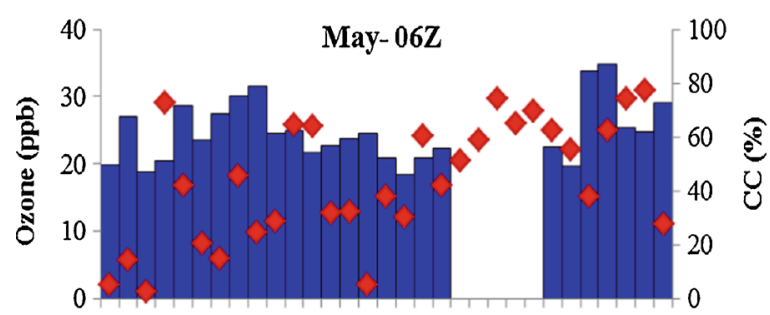

(iii)

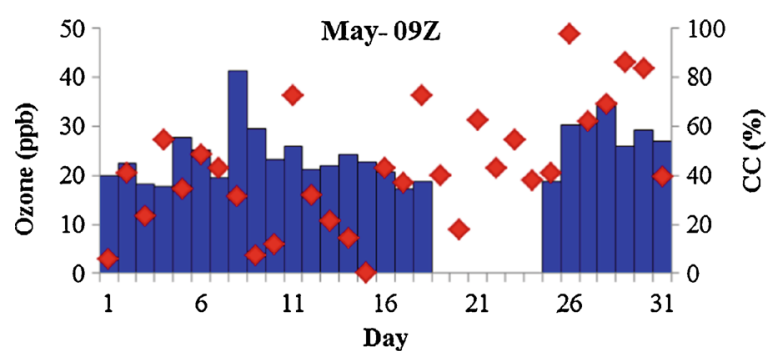

(e)

(iv)
Other meteorological data are also obtained from University of Wyoming website (http://weather. uwyo.edu/) for all necessary calculations.

\subsection{Methodology}

This paper incorporates the study of surface ozone and cloud coverage for one year - 2011. The NOAA ARL website gives the cloud coverage data as percentage (\%) measured at every $3 \mathrm{hrs}$ on a day starting from 00Z. This measurement only accounts for the area of the sky covered with clouds and does not consider other details such as cloud type, albedo or solar radiation receipt. Since we are considering surface ozone production, which is photochemistry driven, only data of 00Z (0530 Local

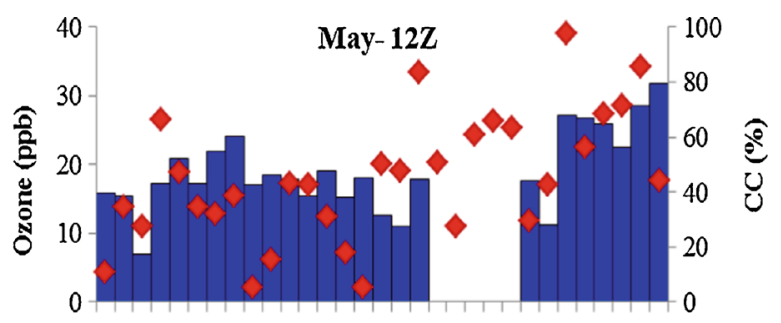

(v)

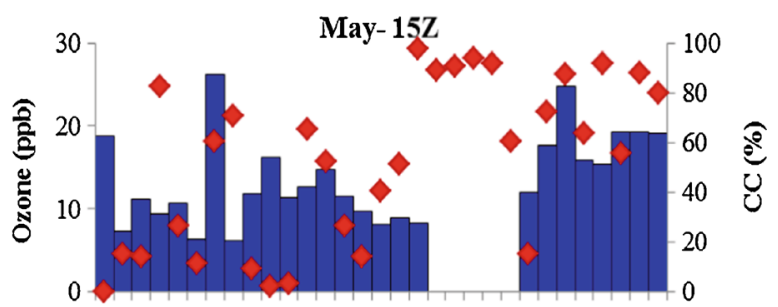

(vi)

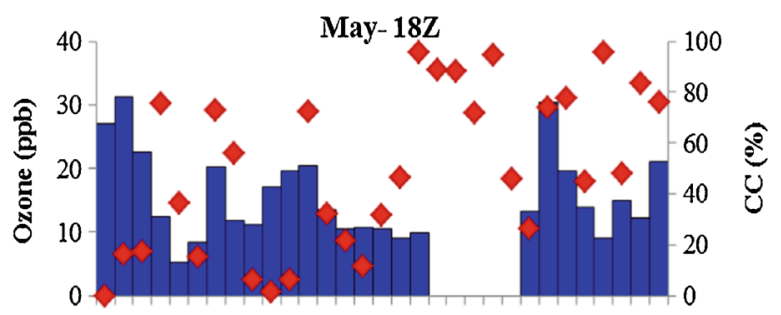

(vii)



(viii)

Figure 2. (e). Monthly variation of surface ozone with cloud coverage for May 2011 at (i) 00Z, (ii) 03Z, (iii) 06Z, (iv) 09Z, (v) $12 \mathrm{Z}$, (vi) $15 \mathrm{Z}$, (vii) $18 \mathrm{Z}$ and (viii) $21 \mathrm{Z}$. 
Time - LT), 03Z (0830 LT), 06Z (1130 LT) and 09Z (1430 LT) are considered for computation here. The photochemical production of ozone is at its best during these times, hence the selection. Along with the surface ozone data, the columnar ozone values are also analysed to find any correlation. Besides this, the seasonal variation of ozone with primary precursor $-\mathrm{NO}_{2}$ and temperature has also been observed.

\section{Results and discussions}

This study entitles continuous monitoring of surface ozone and cloud coverage over Kolkata during a year long period from January to December, 2011. At first, the frequency distribution of cloud coverage is observed (figure 1). The distribution, out of 365 occurrences, mostly shows either clear sky conditions $(0-10 \%)$ or fully covered sky condition (90-100\%) during the entire study period. Thus, we may say that during instances of clear sky condition, presence of surface ozone concentrations is mainly governed by photochemical production induced by high intensity of solar radiation. In case of partially or fully covered sky, the substantial amounts of ozone present may be accounted for due to other meteorological effects. We shall discuss in detail these cases in the coming sections.

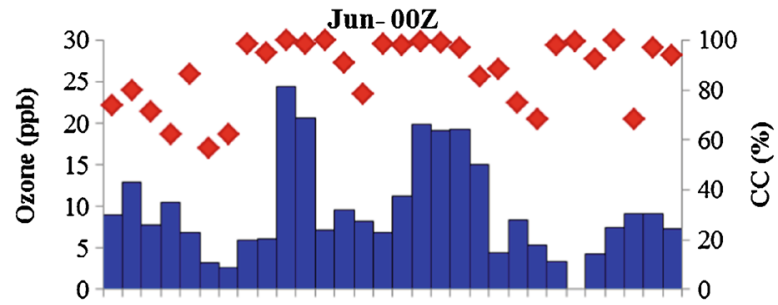

(i)



(ii)

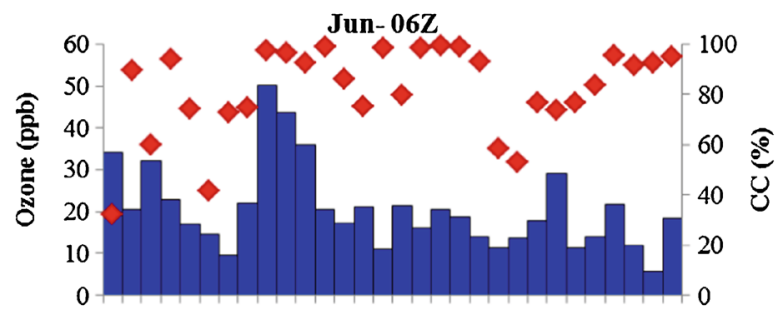

(iii)

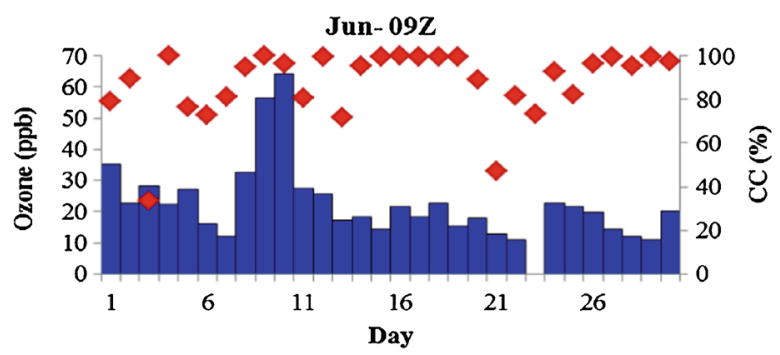

(f)

(iv)

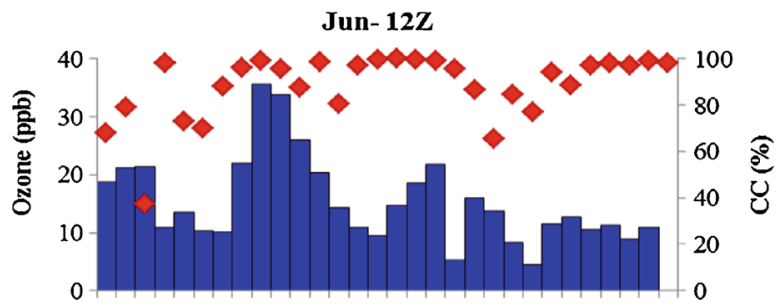

(v)

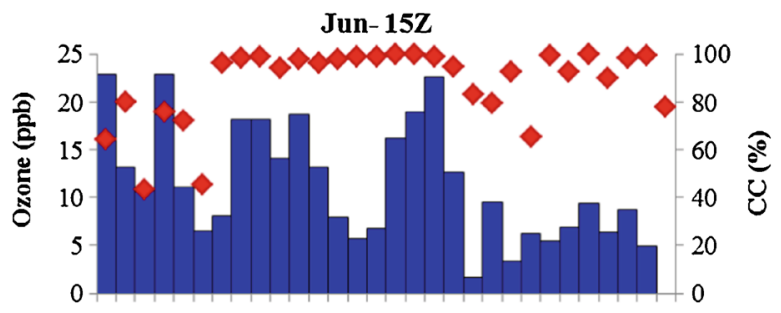

(vi)

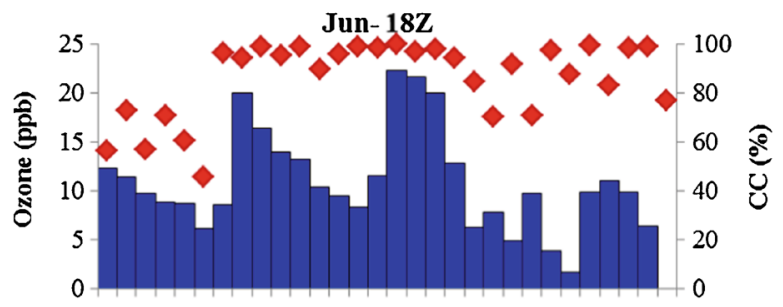

(vii)



(viii)

Figure 2. (f). Monthly variation of surface ozone with cloud coverage for June 2011 at (i) 00Z, (ii) 03Z, (iii) 06Z, (iv) $09 \mathrm{Z}$, (v) $12 \mathrm{Z}$, (vi) $15 \mathrm{Z}$, (vii) $18 \mathrm{Z}$ and (viii) $21 \mathrm{Z}$. 


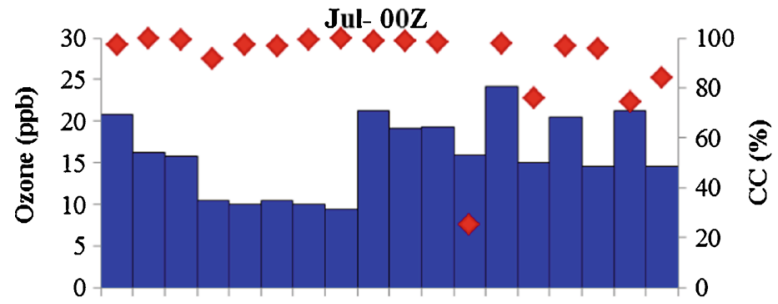

(i)



(ii)



(iii)

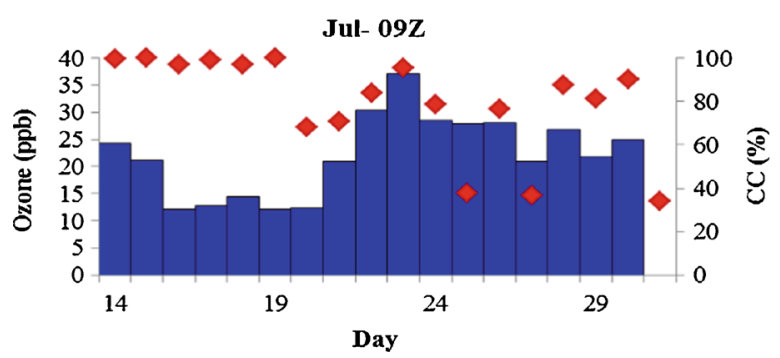

(g)



(v)

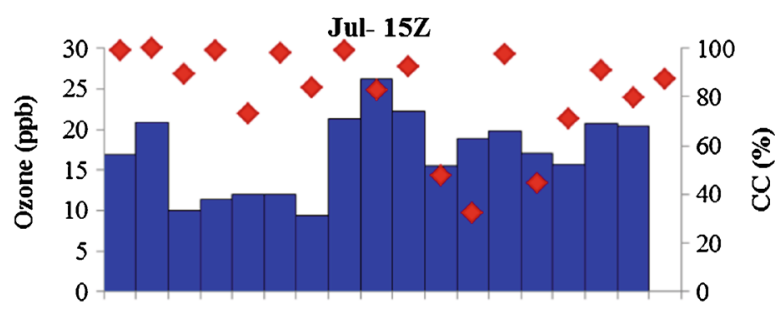

(vi)

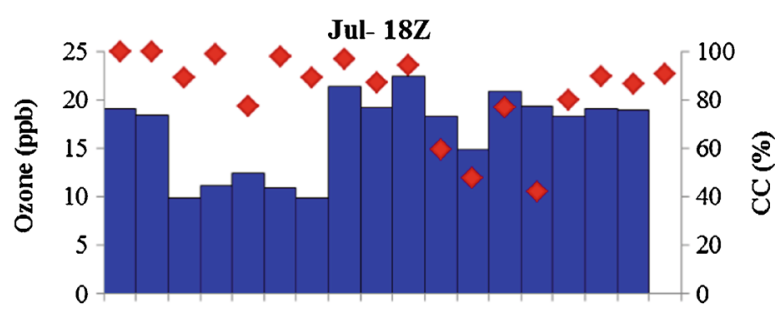

(vii)

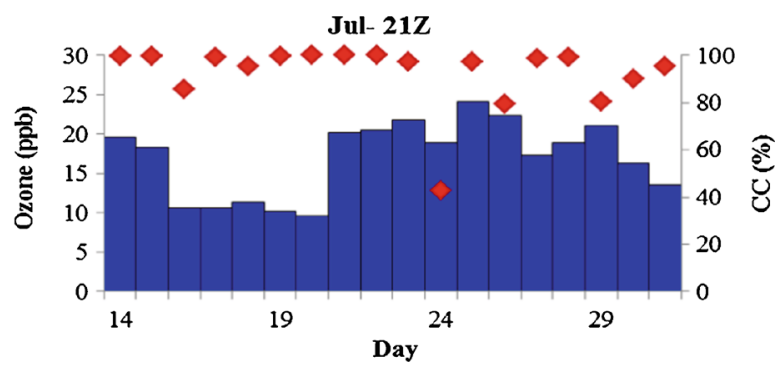

(viii)

Figure 2. (g). Monthly variation of surface ozone with cloud coverage for July 2011 at (i) 00Z, (ii) 03Z, (iii) 06Z, (iv) $09 \mathrm{Z}$, (v) $12 \mathrm{Z}$, (vi) $15 \mathrm{Z}$, (vii) $18 \mathrm{Z}$ and (viii) $21 \mathrm{Z}$.

\subsection{Monthly variation of ozone and cloud coverage}

The monthly variations of surface ozone and cloud coverage for all the months of the study period are plotted and shown in figure $2(\mathrm{a}-1)$. The $\mathrm{x}$-axis represents the date of every month, the primary $y$-axis characterizes surface ozone values which are plotted as columns (blue) and the secondary y-axis represents the cloud coverage values (red dots). For each month, the variations of surface ozone with cloud coverage are plotted at 00 to $21 \mathrm{Z}$. Among all the months studied, the best results are obtained from end of October to February. These months cover the post-monsoon and the winter period of this region (according to the guidelines of India
Meteorological Department). In winter, Kolkata experiences moderately warm days and cool nights as this region falls in the Tropical wet-dry region according to Koppen classification. The cloud coverage over eastern India is lesser than the other times of the year and for the maxmum time it is cloudless. This is clear from the figures as in most of the cases cloud coverage values show very low percentage of coverage. Due to clear sky condition, maximum solar radiation reaches the earth surface around this time, so the surface ozone content increases. In most of the cases, it is observed that the concentration of surface ozone and cloud cove rage is inversely related. The result is expected as surface ozone is photochemically produced and in 




(i)

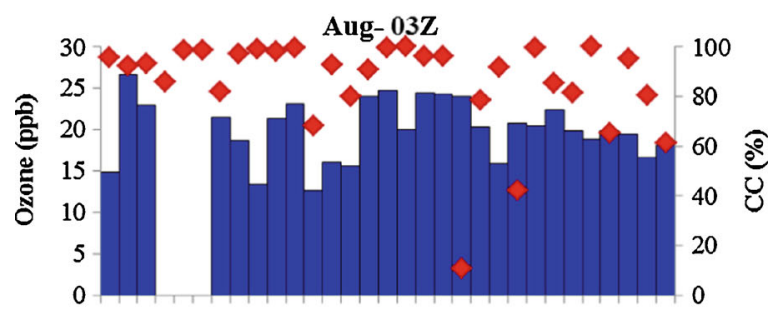

(ii)



(iii)

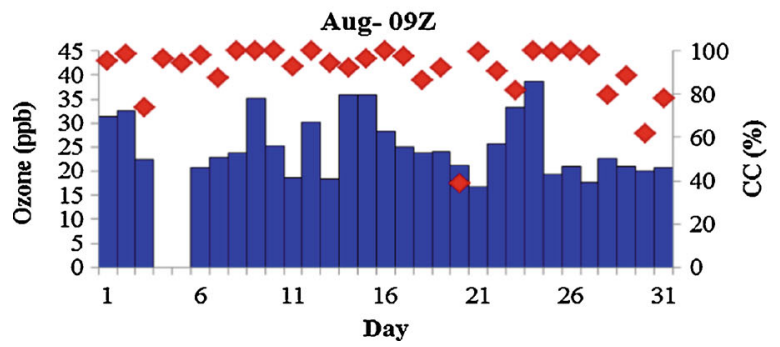

(h)

(iv)

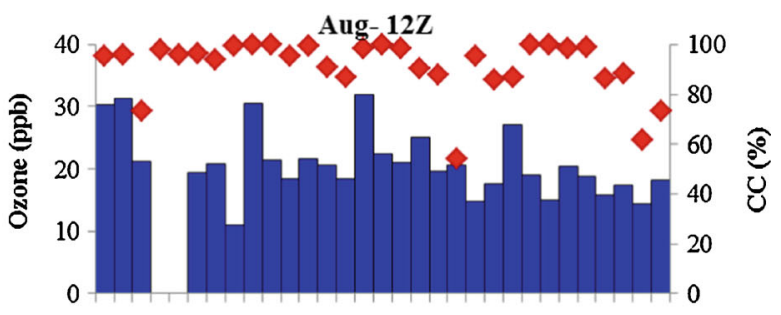

(v)

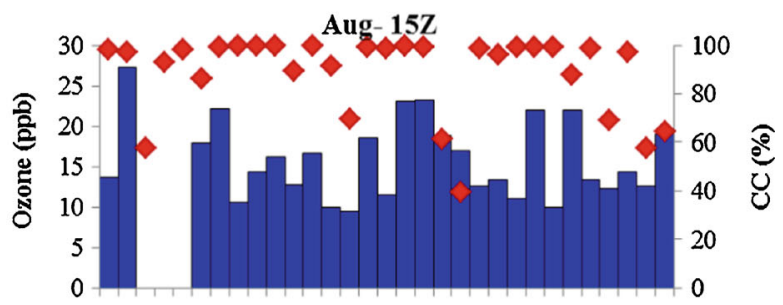

(vi)



(vii)

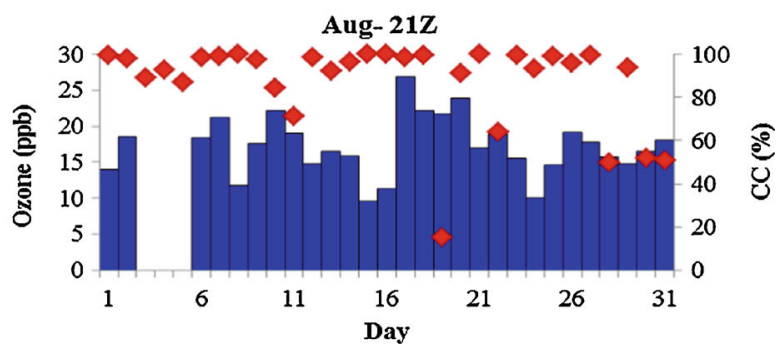

(viii)

Figure 2. (h). Monthly variation of surface ozone with cloud coverage for August 2011 at (i) 00Z, (ii) 03Z, (iii) 06Z, (iv) 09Z, (v) 12Z, (vi) 15Z, (vii) $18 \mathrm{Z}$ and (viii) $21 \mathrm{Z}$.

the presence of clouds less amounts of UV radiation penetrates to reach the surface and hence the production is less.

Ozone near the surface is formed through a complex series of reactions involving the action of sunlight in presence of nitrogen oxides $\left(\mathrm{NO}_{\mathrm{x}}\right)$ and volatile organic compounds (Haagen-Smit 1952; Crutzen 1979). Profuse amounts of CO, non-methane hydrocarbons (NMHCs), and $\mathrm{NO}_{\mathrm{x}}$ are found in the tropical region due to large-scale biomass burning. Substantial levels of these gases are also released from automobile emissions.

Tropospheric ozone forms by reactions of oxides of nitrogen $\left(\mathrm{NO}_{\mathrm{x}}\right)$ and volatile organic compounds
(VOCs) in the presence of solar radiation. Ozone photochemistry occurs when $\mathrm{NO}_{2}$ is photolyzed in sunlight. Ozone formation is the result of the following reactions (Seinfeld and Pandis 2006):

$$
\begin{gathered}
\mathrm{NO}_{2}+\mathrm{hv} \rightarrow \mathrm{NO}+\mathrm{O}\left({ }^{3} \mathrm{P}\right)(\text { where } \mathrm{hv}<420 \mathrm{~nm}) \\
\mathrm{O}\left({ }^{3} \mathrm{P}\right)+\mathrm{O}_{2}+\mathrm{M} \rightarrow \mathrm{O}_{3}+\mathrm{M}
\end{gathered}
$$

Once formed, ozone reacts with $\mathrm{NO}$ to regenerate $\mathrm{NO}_{2}$.

$$
\mathrm{O}_{3}+\mathrm{NO} \rightarrow \mathrm{NO}_{2}+\mathrm{O}_{2}
$$




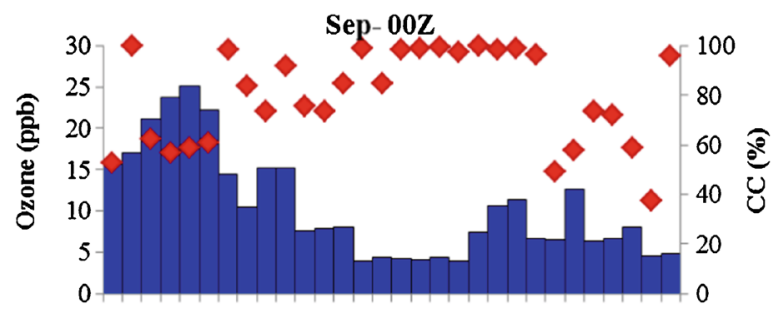

(i)



(ii)

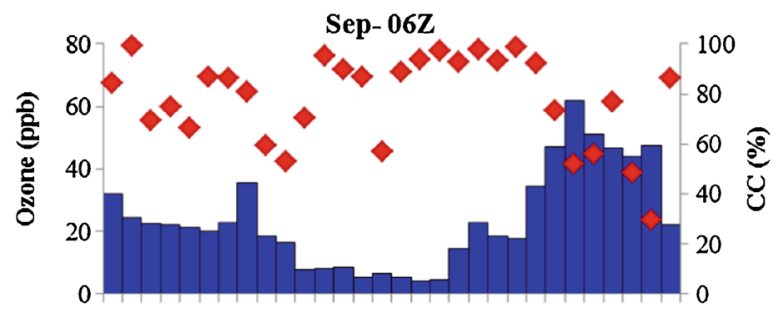

(iii)

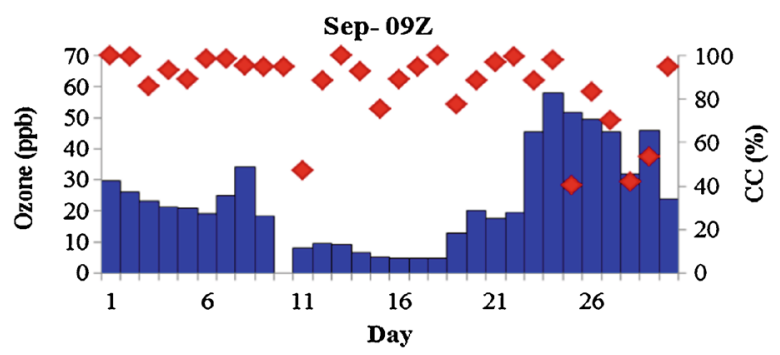

(i)

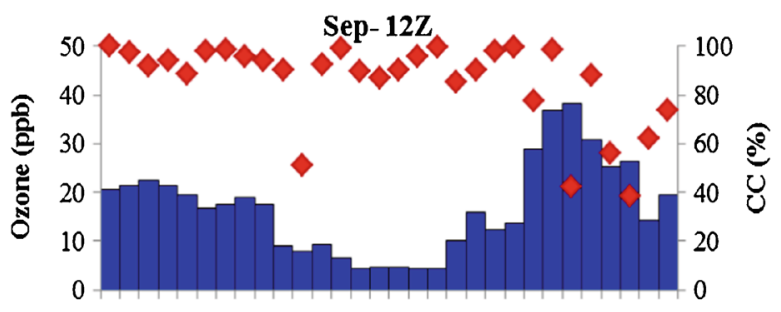

(v)



(vi)

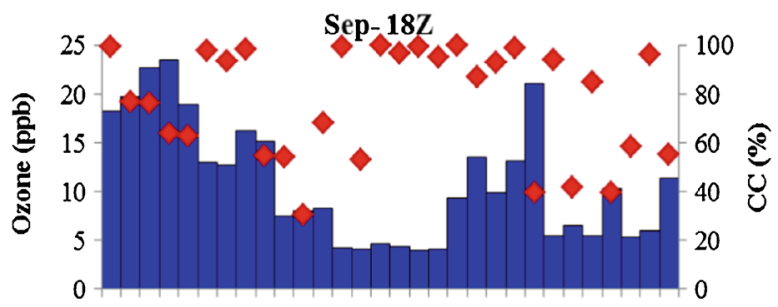

(vii)

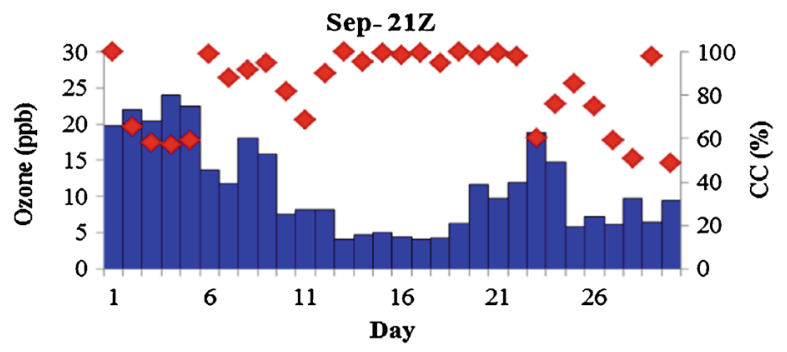

(viii)

Figure 2. (i). Monthly variation of surface ozone with cloud coverage for September 2011 at (i) 00Z, (ii) 03Z, (iii) 06Z, (iv) $09 \mathrm{Z}$, (v) 12Z, (vi) 15Z, (vii) $18 \mathrm{Z}$ and (viii) $21 \mathrm{Z}$.

Net ozone production is not possible unless a peroxy radical is present to react with $\mathrm{NO}$ to regenerate the $\mathrm{NO}_{2}$ without destroying an ozone molecule as in reaction (3).

$$
\begin{aligned}
& \mathrm{RO}_{2}+\mathrm{NO} \rightarrow \mathrm{NO}_{2}+\mathrm{RO} \\
& \text { (where } \mathrm{R} \text { can be: } \mathrm{H}, \quad \mathrm{CH}_{3}, \mathrm{C}_{2} \mathrm{H}_{5}, \text { etc.) }
\end{aligned}
$$

In the Indian subcontinent, higher water content in the atmosphere, also favours the photochemical production of ozone. Besides transport and dispersion, air mass plays a pivotal role in formation and building up of ozone.

\subsection{Seasonal variation of surface ozone with its precursor, columnar ozone and meteorological parameters}

The seasonal variation of surface ozone, its precursor $\mathrm{NO}_{2}$ and columnar ozone over Kolkata is presented in figure 3 . The monthly average values of surface ozone (blue line in the plot) in 2011 shows a more or less smooth trend with higher values in the winter period and lower during the monsoon. The monthly average of its precursor $-\mathrm{NO}_{2}$ (red line in the plot) - shows a maximum at the beginning of the year, during winter (January-February 2011). The values steadily decrease during the 


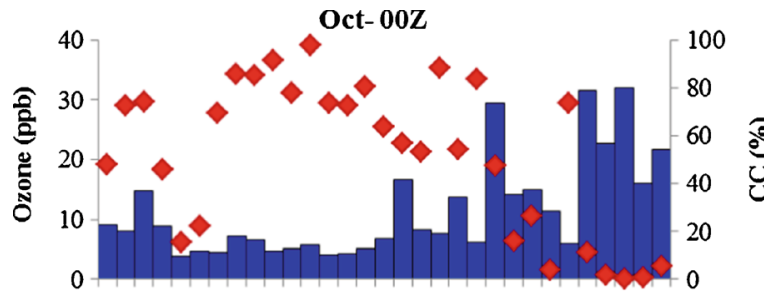

(i)

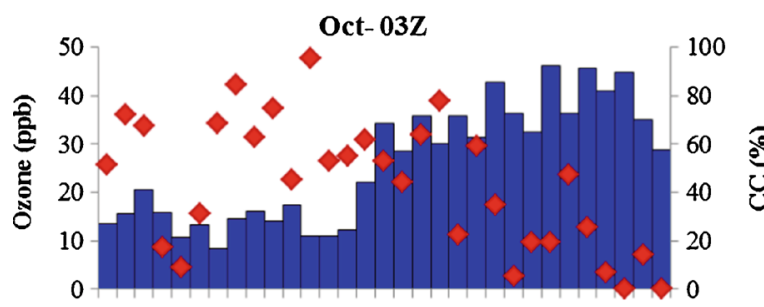

(ii)



(iii)

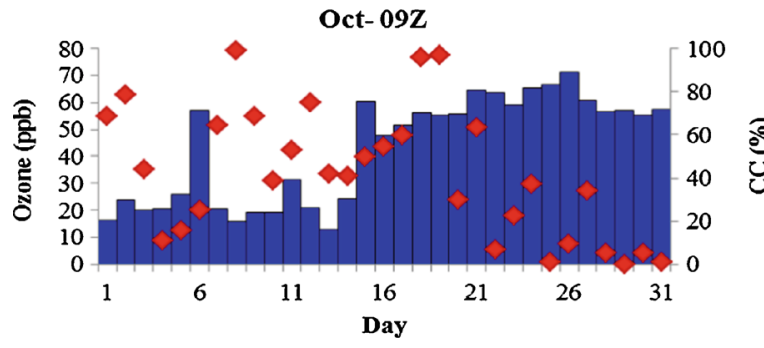

(j)

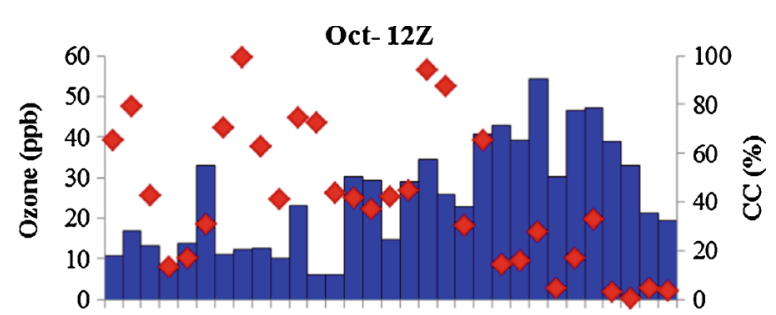

(v)



(vi)

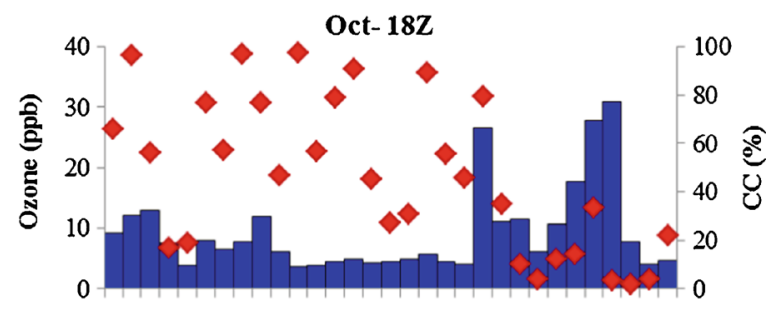

(vii)



(viii)

Figure 2. (j). Monthly variation of surface ozone with cloud coverage for October 2011 at (i) 00Z, (ii) 03Z, (iii) 06Z, (iv) 09Z, (v) 12Z, (vi) 15Z, (vii) $18 \mathrm{Z}$ and (viii) $21 \mathrm{Z}$.

pre-monsoon months (March-May 2011) and attain a minimum during the monsoon period. From late monsoon onwards (September-October 2011), surface $\mathrm{NO}_{2}$ concentration again starts building up. The trend of the columnar ozone concentration as obtained from the OMI shows maximum values during the pre-monsoon months (March-May 2011). If we minutely observe the trends of both the surface and the columnar ozone values, we find a similarity in the changes of concentration during March-June 2011, when both show a gradual decreasing tendency. Again during September-October 2011, the concentration increases and then decreases till December 2011. Thus it may be suggested that even though in a very small extent, the columnar ozone concentration of Kolkata has a certain amount of influence on the overall surface concentration of ozone. The seasonal variation among the surface ozone and $\mathrm{NO}_{2}$ concentration, however, show no direct correlation amongst themselves.

Along with the seasonal variation of the gases, seasonal temperature profile and $\mathrm{CC}$ values are also computed and plotted in figure 4. The blue and the red lines represent the monthly average temperature and CC over Kolkata for the entire year of 2011. As expected, the CC is maximum during the monsoon months: June-September 2011. The highest amount of clear sky is observed during the winter, followed by post-monsoon. The average 




(i)

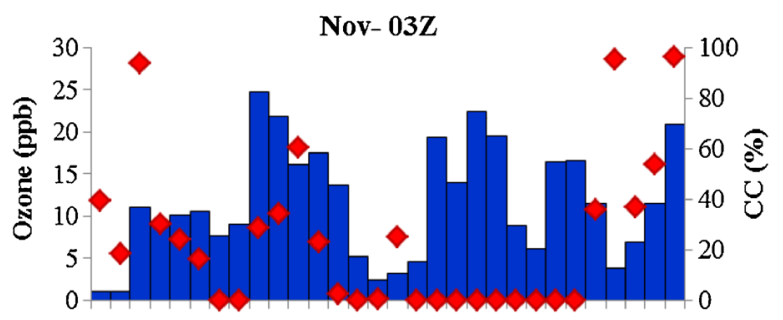

(ii)

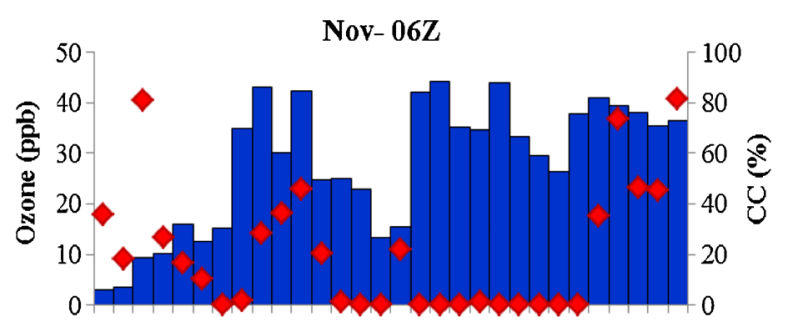

(iii)

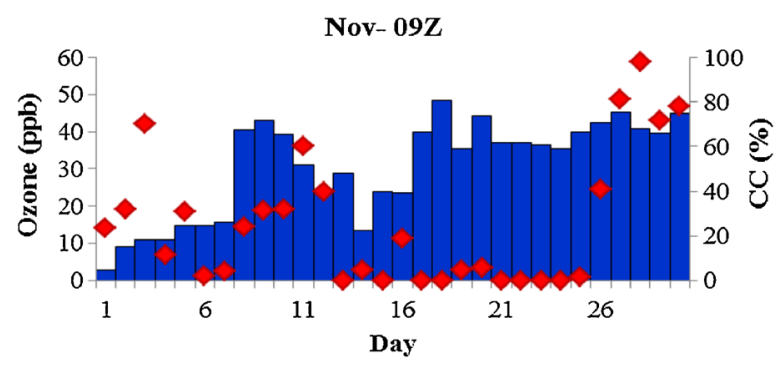

(k)

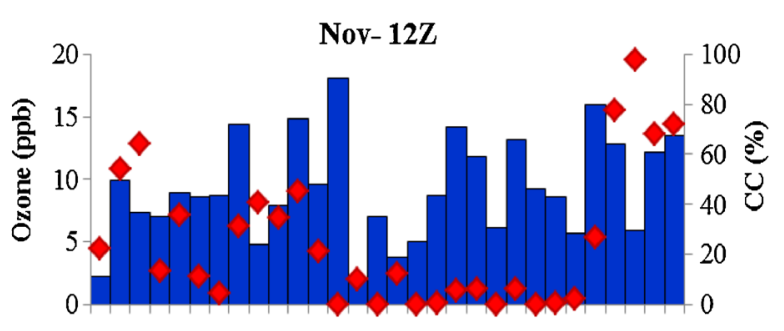

(v)

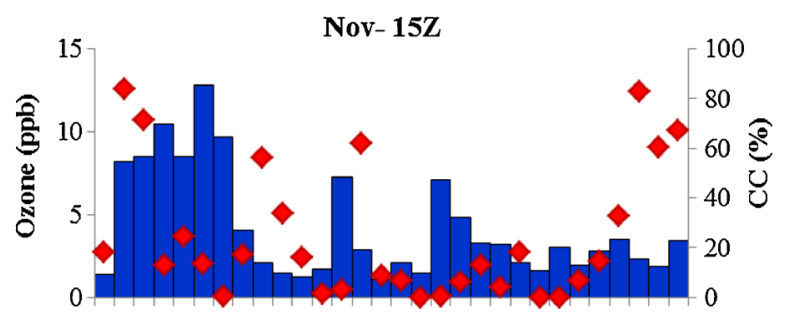

(vi)

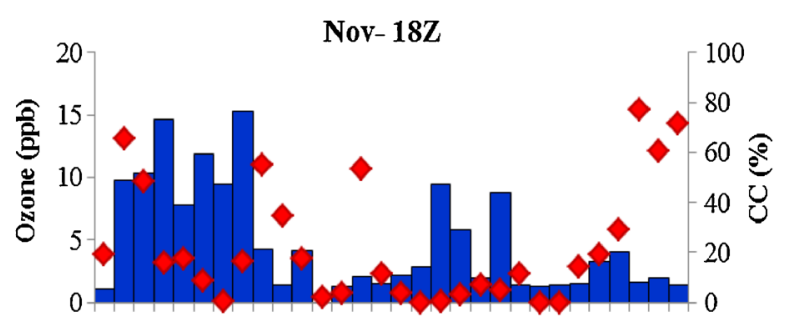

(vii)

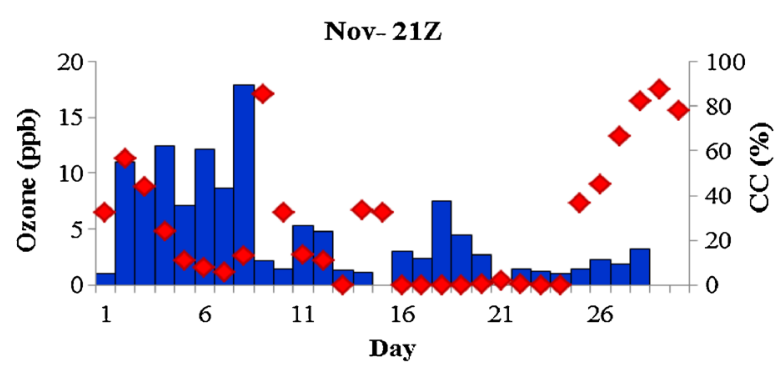

(viii)

Figure 2. (k) Monthly variation of surface ozone with cloud coverage for November 2011 at (i) 00Z, (ii) 03Z, (iii) 06Z, (iv) 09Z, (v) 12Z, (vi) 15Z, (vii) $18 \mathrm{Z}$ and (viii) $21 \mathrm{Z}$.

monthly temperature illustrates the typi cal profile that of a region of tropical wet and dry climate. The lowest temperatures are recorded during the winter months followed by the post-monsoon. For rest of the year, the temperature remains more or less high in the range of $25^{\circ}-35^{\circ} \mathrm{C}$.

\subsection{Correlation study}

Correlations between surface ozone and cloud coverage are also studied and presented in figure 5 . Since there is a time lag between the amount of ozone formed to the cloud coverage, the surface ozone data of $30 \mathrm{~min}$ later than the cloud coverage are considered for computation. The $\mathrm{x}$ axis and $y$-axis represent CC (\%) and surface ozone $(\mathrm{ppb})$, respectively. The coefficient of determination $\left(R^{2}\right)$ of ozone vs. cloud coverage shows very poor correlation. The $R^{2}$ values at 00Z, 03Z, 06Z, 09Z, 12Z, 15Z, 18Z and 21Z are 0.032, 0.0, 0.105, $0.159,0.018,0.061,0.063$, and 0.042 , respectively. An interesting trend is obtained. From 06Z to $12 \mathrm{Z}$, there is a negative correlation among surface ozone and $\mathrm{CC}$. This indicates that during daytime (06Z-12Z), amount of ozone at the surface is driven by photochemical production from its precursors. Hence, higher the CC, lesser is the amount of surface ozone. Again as night approaches (15-00Z), the trend is reversed. This signifies that 




(i)



(ii)



(iii)

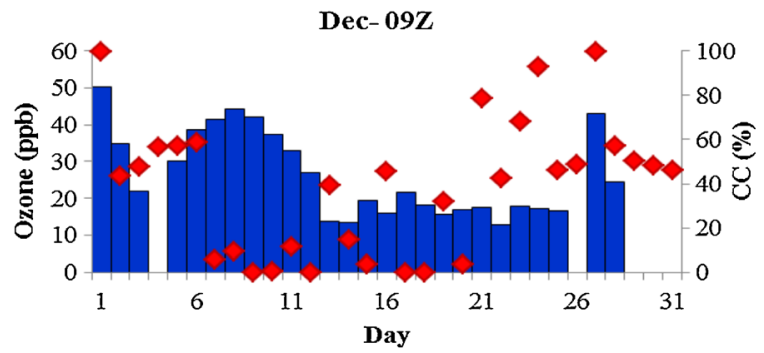

(I)



(v)

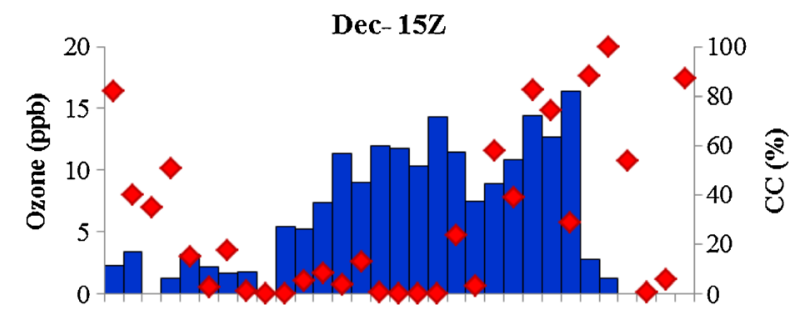

(vi)



(vii)

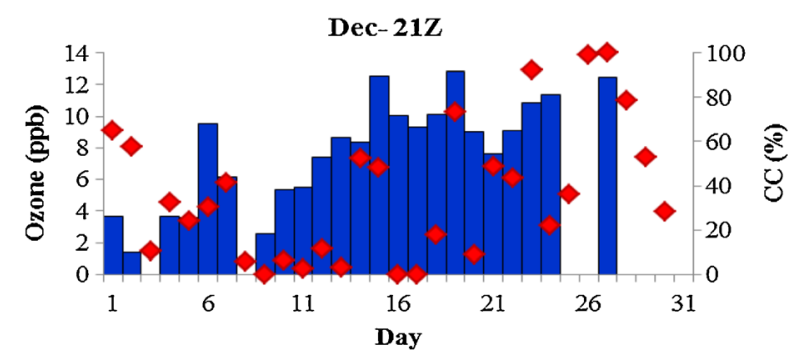

(viii)

Figure 2. (I). Monthly variation of surface ozone with cloud coverage for December 2011 at (i) 00Z, (ii) 03Z, (iii) 06Z, (iv) 09Z, (v) 12Z, (vi) $15 \mathrm{Z}$, (vii) $18 \mathrm{Z}$ and (viii) $21 \mathrm{Z}$.



Figure 3. Seasonal variation of surface ozone, $\mathrm{NO}_{2}$ and columnar ozone over Kolkata for 2011. 


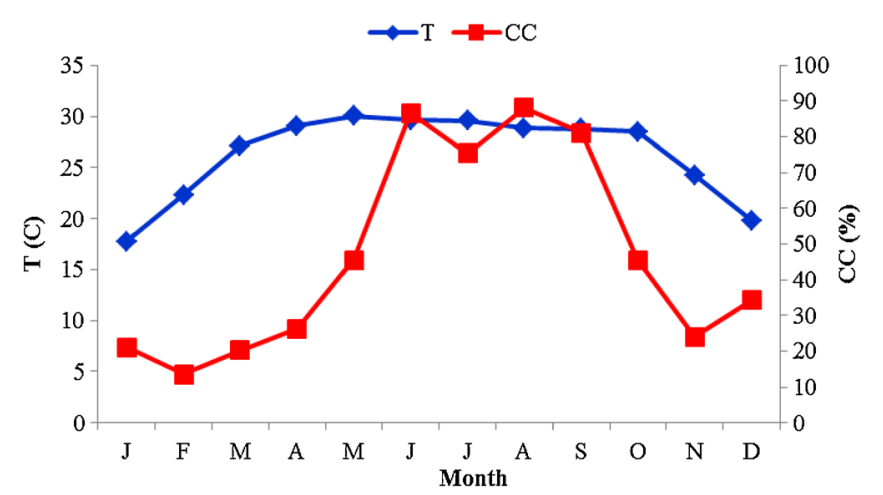

Figure 4. Seasonal variation of temperature $(\mathrm{T})$ and cloud coverage (CC) over Kolkata for 2011.
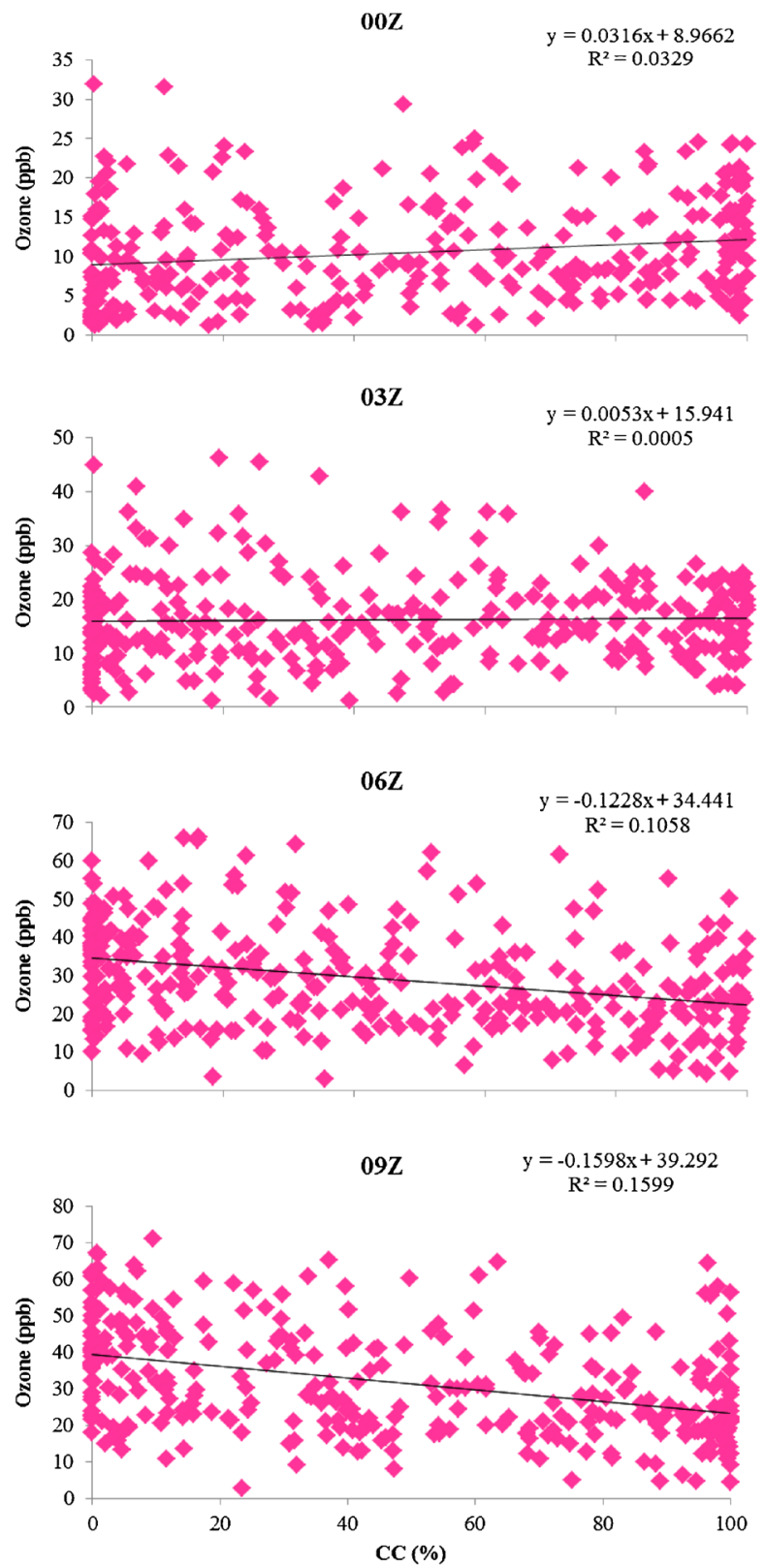

in the absence of sunlight, other meteorological parameters have an active role to play in the presence of surface ozone concentration. Although very poorly correlated, the significance of such poor correlations among these two parameters may be that surface ozone production is not primarily dependant on the cloud coverage at our site. Other meteorological parameters along with different emission sources are responsible. These results are also supported by the fact that during the study periods several anomaly days have been observed on which the trend between surface ozone and cloud coverage have been found just the reverse. More about the anomaly days is discussed in the following section.
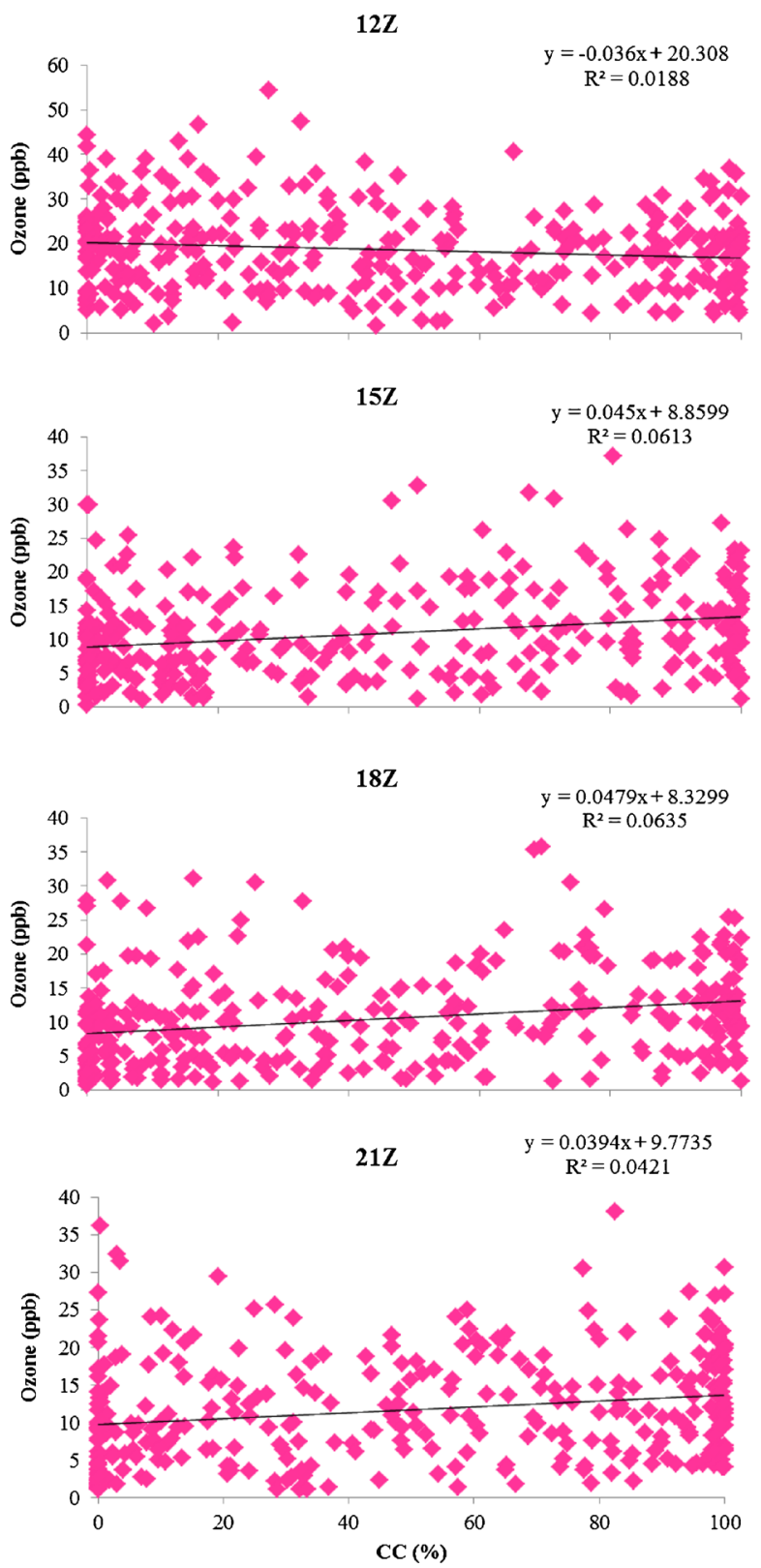

Figure 5. Correlation between surface ozone (ppb) and cloud coverage (\%) at (a) 00Z, (b) 03Z, (c) 06Z, (d) 09Z, (e) 12Z, (f) $15 \mathrm{Z}$, (g) $18 \mathrm{Z}$ and (h) $21 \mathrm{Z}$. 
Table 1(a). Basis of assumption for the selection of anomaly days.

\begin{tabular}{|c|c|c|c|}
\hline & \multicolumn{3}{|c|}{ Threshold Values } \\
\hline & $\begin{array}{c}03 Z \\
\text { Ozone }(\mathrm{ppb}) \\
{[\text { Median }-15.37]}\end{array}$ & $\begin{array}{c}06 \mathrm{Z} \\
\text { Ozone }(\mathrm{ppb}) \\
{[\text { Median }-27.37]}\end{array}$ & $\begin{array}{c}09 \mathrm{Z} \\
\text { Ozone }(\mathrm{ppb}) \\
{[\text { Median }-29.43]}\end{array}$ \\
\hline Anomaly due to high ozone and high CC $(>50 \%)$ & $>23.05$ & $>41.05$ & $>44.15$ \\
\hline Anomaly due to low ozone and low CC $(<50 \%)$ & $<7.68$ & $<13.69$ & $<14.72$ \\
\hline
\end{tabular}

Table 1(b). Dates on which anomaly were observed due to high ozone and high cloud coverage.

\begin{tabular}{|c|c|c|}
\hline Date & $\mathrm{CC}(\%)$ & Ozone (ppb) \\
\hline \multicolumn{3}{|l|}{$03 \mathrm{Z}$} \\
\hline 16.10 .11 & 52.9 & 34.25 \\
\hline 26.09 .11 & 53.4 & 36.54 \\
\hline 08.05 .11 & 55.9 & 23.53 \\
\hline 01.02 .11 & 59.1 & 26.10 \\
\hline 21.10 .11 & 59.1 & 31.28 \\
\hline 25.09 .11 & 60.4 & 36.28 \\
\hline 28.05 .11 & 62.0 & 23.57 \\
\hline 05.09 .11 & 62.1 & 24.48 \\
\hline 18.10 .11 & 63.5 & 35.84 \\
\hline 01.09 .11 & 74.6 & 26.59 \\
\hline 19.10 .11 & 77.5 & 30.01 \\
\hline 03.01 .11 & 78.9 & 24.27 \\
\hline 30.07 .11 & 82.5 & 23.31 \\
\hline 23.07 .11 & 82.9 & 25.05 \\
\hline 27.09 .11 & 84.4 & 39.96 \\
\hline 08.09 .11 & 84.8 & 24.61 \\
\hline 15.08 .11 & 90.8 & 24.02 \\
\hline 02.08 .11 & 92.3 & 26.63 \\
\hline 24.07 .11 & 94.8 & 23.35 \\
\hline 16.07 .11 & 95.2 & 23.24 \\
\hline 19.08 .11 & 96.2 & 24.31 \\
\hline 18.08 .11 & 96.3 & 24.41 \\
\hline 14.07 .11 & 97.8 & 23.43 \\
\hline 29.07 .11 & 97.9 & 23.47 \\
\hline 15.07 .11 & 99.2 & 23.88 \\
\hline 16.08 .11 & 99.4 & 24.77 \\
\hline 11.08 .11 & 99.5 & 23.13 \\
\hline 10.06 .11 & 99.6 & 24.69 \\
\hline \multicolumn{3}{|l|}{$06 Z$} \\
\hline 21.10 .11 & 51.2 & 57.21 \\
\hline 25.09 .11 & 51.9 & 61.96 \\
\hline 26.09 .11 & 56.0 & 51.04 \\
\hline 01.02 .11 & 58.8 & 53.88 \\
\hline 23.03 .11 & 62.7 & 42.90 \\
\hline 18.10 .11 & 71.5 & 61.49 \\
\hline 24.09 .11 & 73.6 & 47.33 \\
\hline 27.09 .11 & 76.6 & 46.89 \\
\hline 19.10 .11 & 77.3 & 52.24 \\
\hline 15.08 .11 & 88.0 & 55.28 \\
\hline 01.08 .11 & 94.0 & 43.23 \\
\hline 10.06 .11 & 96.6 & 43.63 \\
\hline 09.06.11 & 97.3 & 50.04 \\
\hline
\end{tabular}

Table 1(b). (Continued.)

\begin{tabular}{lcc}
\hline Date & CC $(\%)$ & Ozone $(\mathrm{ppb})$ \\
\hline $\mathbf{0 9 Z}$ & & \\
29.09 .11 & 53.2 & 45.85 \\
16.10 .11 & 54.3 & 47.62 \\
12.01 .11 & 55.1 & 44.27 \\
17.10 .11 & 59.8 & 51.36 \\
28.01 .11 & 60.6 & 61.00 \\
21.10 .11 & 63.6 & 64.69 \\
27.09 .11 & 70.0 & 45.44 \\
30.11 .11 & 78.0 & 44.86 \\
27.11 .11 & 81.3 & 45.13 \\
26.09 .11 & 83.1 & 49.49 \\
23.09 .11 & 88.4 & 45.43 \\
18.10 .11 & 96.1 & 56.04 \\
10.06 .11 & 96.5 & 64.34 \\
19.10 .11 & 96.9 & 55.42 \\
24.09 .11 & 98.0 & 57.89 \\
01.12 .11 & 99.5 & 50.43 \\
09.06 .11 & 100.0 & 56.40 \\
\hline
\end{tabular}

\subsection{Anomaly observed in the correlation study}

Regardless of the good results, certain anomaly days have been observed which are tabulated in table 1 . The table represents the anomaly dates at three different times - 03Z, 06Z, and 21Z. The assumptions based on which the anomaly days selected are tabulated in table 1(a). The anomalies may be categorized basically into two types: when ozone concentrations are higher despite high CC (table 1b) and low ozone concentrations with low CC (table 1c). In both the cases, the time period of $00 \mathrm{Z}$ and $12-21 \mathrm{Z}$ are neglected. This is due to the fact that since we are focussing on ozone production, the phenomenon of photochemical production of ozone is not very predominant at these hours in this part of the world. Thus the amount of surface ozone present at these times is mainly contributed from either residual amounts from previous days production or from advection of airmass from nearby or distant areas. 
Table 1(c). Dates on which anomaly were observed due to low ozone and low cloud coverage.

\begin{tabular}{|c|c|c|}
\hline Date & $\mathrm{CC}(\%)$ & Ozone (ppb) \\
\hline \multicolumn{3}{|l|}{$03 \mathrm{Z}$} \\
\hline 13.02 .11 & 0 & 3.56 \\
\hline 22.02 .11 & 0 & 7.61 \\
\hline 25.02 .11 & 0 & 4.45 \\
\hline 13.03 .11 & 0 & 3.03 \\
\hline 11.04 .11 & 0 & 6.44 \\
\hline 14.11 .11 & 0 & 5.20 \\
\hline 17.11 .11 & 0 & 4.66 \\
\hline 23.11 .11 & 0 & 6.14 \\
\hline 11.12 .11 & 0 & 7.35 \\
\hline 12.12 .11 & 0 & 5.94 \\
\hline 15.11 .11 & 0.3 & 2.51 \\
\hline 10.12 .11 & 1.3 & 2.22 \\
\hline 15.03 .11 & 3.6 & 6.61 \\
\hline 01.01.11 & 4.9 & 4.74 \\
\hline 10.03 .11 & 5.7 & 2.67 \\
\hline 14.01 .11 & 8.2 & 6.10 \\
\hline 14.02 .11 & 14.3 & 4.88 \\
\hline 30.01 .11 & 15.6 & 4.81 \\
\hline 02.11 .11 & 18.3 & 1.14 \\
\hline 05.03.11 & 18.8 & 6.10 \\
\hline 16.11 .11 & 25.1 & 3.26 \\
\hline 27.03 .11 & 25.2 & 5.56 \\
\hline 04.12 .11 & 27.1 & 1.61 \\
\hline 17.02 .11 & 31.2 & 6.62 \\
\hline 02.12 .11 & 33.6 & 4.39 \\
\hline 07.01 .11 & 34.2 & 7.59 \\
\hline 11.03 .11 & 34.2 & 6.67 \\
\hline 28.11 .11 & 36.8 & 6.95 \\
\hline 01.11 .11 & 39.4 & 1.13 \\
\hline 03.12 .11 & 46.6 & 2.56 \\
\hline 29.03 .11 & 47.3 & 5.14 \\
\hline \multicolumn{3}{|l|}{$06 \mathrm{Z}$} \\
\hline 14.03 .11 & 0 & 9.86 \\
\hline 15.11 .11 & 0.2 & 13.28 \\
\hline 10.03 .11 & 5.3 & 10.88 \\
\hline 14.01 .11 & 7.7 & 9.44 \\
\hline 06.11 .11 & 10.3 & 12.48 \\
\hline 14.12 .11 & 12.6 & 13.43 \\
\hline 27.03 .11 & 18.1 & 13.25 \\
\hline 02.11.11 & 18.4 & 3.48 \\
\hline 13.12 .11 & 26.1 & 10.16 \\
\hline 04.11 .11 & 26.7 & 10.25 \\
\hline 21.12 .11 & 35.0 & 12.68 \\
\hline 01.11.11 & 35.5 & 2.88 \\
\hline \multicolumn{3}{|l|}{$09 \mathrm{Z}$} \\
\hline 14.11 .11 & 4.6 & 13.34 \\
\hline 04.11 .11 & 11.6 & 10.84 \\
\hline 14.12 .11 & 14.4 & 13.51 \\
\hline 01.11.11 & 23.4 & 2.84 \\
\hline 02.11 .11 & 32.0 & 9.05 \\
\hline 13.12 .11 & 39.3 & 13.72 \\
\hline 13.10 .11 & 41.7 & 12.85 \\
\hline 22.12 .11 & 42.2 & 12.87 \\
\hline 11.09 .11 & 47.3 & 7.92 \\
\hline
\end{tabular}

These anomaly situations can only be justified on the basis of horizontal wind transport. Though insolation is the driving force for ozone production in the troposphere, concentrations of the precursors are also a matter of concern here. In case of low ozone concentrations with low cloud coverage, it may be suggested that even with high insolation, either the precursor concentrations were low or the ozone produced was dispersed due to horizontal wind trandsport. On the otherhand, in the opposite case, high ozone values may result from either windborne transport or due to certain meteorological conditions, which have prevented the previously produced ozone from getting dispersed.

\section{Concluding remarks}

Clouds are an essential component of weather on Earth. They are condensed atmospheric moisture the form of minute water droplets or ice crystals. In addition to solar UV radiation and precursor gases, cloud coverage plays a major role in contributing to the ground level ozone of a place. Under no cloud or high transparent cloud cover condition, more insolation reaches the ground level favouring the photochemical processes that generate ground level ozone. So, the expected results should be with increase in cloud cover, ground level ozone decreases. The presence of UV radiation is an essential condition for the production of surface ozone by $\mathrm{NO}_{2}$ photolysis reaction. The high cloud coverage prevents the UV radiation to reach the surface and for this reason less amount of surface ozone is formed. The study over Kolkata shows good connection between surface ozone and cloud coverage. Apart from this relation, the seasonal variation of surface ozone along with its precursor $\mathrm{NO}_{2}$, columnar ozone, and temperature indicate a highly complex relationship among these species. Even though, good relation was obtained at times, certain anomalies were observed, which clearly indicate the dominant effect of other meteorological parameters responsible for these anomalies. Thus all these parameters are singularly ineffective in explaining the presence of surface ozone over Kolkata. Rather, a combined effect of all of them along with other meteorological aspects such as convective transport, inversion, etc., is helpful in elucidating the anomaly instances.

\section{Acknowledgements}

The authors sincerely thank the ISRO-AT-CTM programme for funding the project and CSIR for funding the Research Fellowship of Debreka Ghosh. They are also grateful to the Department of 
Instrumentation and Electronics Engineering, Jadavpur University, for providing a laboratory to set up the necessary instruments to carry out the project. The authors greatfully acknowledge the NOAA Air Resources Laboratory (ARL) for providing the meteorological data used in this publication.

\section{References}

Alexandris D, Varotsos C, Ya Kondratyev K and Chronopoulos G 1999 On the altitude dependence of solar effective UV; Physics and Chemistry of the Earth, Part C: Solar, Terr. Planet. Sci. 24 515-517.

Burrows W R 1997 CART regression models for predicting $\mathrm{UV}$ radiation at the ground in the presence of cloud and other environmental factors; J. Appl. Meteorol. 36 531-544.

Calbó J, Pagès D and González J A 2005 Empirical studies of cloud effects on UV radiation: A review; Rev. Geophys. 43153.

Crutzen P J 1979 The role of $\mathrm{NO}$ and $\mathrm{NO}_{2}$ in the chemistry of the troposphere and stratosphere; Ann. Rev. Earth Planet. Sci. 7 443-472.

Estupiñán J G, Raman S, Crescenti G H, Streicher J J and Barnard W F 1996 Effects of clouds and haze on UV-B radiation; J. Geophys. Res.: Atmospheres (1984-2012) 101 16,807-16,816.

Ghose M K, Paul R and Banerjee S K 2004 Assessment of the impacts of vehicular emissions on urban air quality and its management in Indian context: The case of Kolkata (Calcutta); Environ. Sci. Policy 7 345-351.

Ghosh D, Lal S and Sarkar U 2013 High nocturnal ozone levels at a surface site in Kolkata, India: Trade-off between meteorology and specific nocturnal chemistry; Urban Climate 5 82-103.

Glandorf M, Arola A, Bais A and Seckmeyer G 2005 Possibilities to detect trends in spectral UV irradiance; Theoret. Appl. Climatol. 81 33-44.

Haagen-Smit A J 1952 Chemistry and physiology of Los Angeles smog; Industrial \& Engineering Chemistry 44 1342-1346.

Iqbal M 1983 An introduction to solar radiation; Elsevier.

Jana P K, Saha D K and Midya S K 2010 Effect of cloud on atmospheric ozone formation over Kolkata $\left(22^{\circ} 34^{\prime} \mathrm{N}\right.$, $\left.88^{\circ} 24^{\prime} \mathrm{E}\right)$, India; Ind. J. Phys. 84 367-375.

Jana P K, Saha I, Mukhopadhyay S and Sarkar D 2011 Effect of cloud on atmospheric ozone formation over Hyderabad $\left(17.27^{\circ} \mathrm{N}, 78.28^{\circ} \mathrm{E}\right)$, India; Ind. J. Phys. 85 1569-1580.
Kerr J B and McElroy C T 1995 Total ozone measurements made with the Brewer ozone spectrophotometer during STOIC 1989; J. Geophys. Res.: Atmospheres (1984-2012) $1009225-9230$.

Kiehl J T, Schneider T L, Portmann R W and Solomon S 1999 Climate forcing due to tropospheric and stratospheric ozone; J. Geophys. Res.: Atmospheres (19842012) $10431,239-31,254$.

Kondratyev K Y and Varotsos C A 2001 Global tropospheric ozone dynamics; Environ. Sci. Pollut. Res. 8 113-119.

López M L, Palancar G G and Toselli B M 2009 Effect of different types of clouds on surface UV-B and total solar irradiance at southern mid-latitudes: CMF determinations at Córdoba, Argentina; Atmos. Environ. 43 3130-3136.

Mallik C, Ghosh D, Ghosh D, Sarkar U, Lal S and Venkataramani S 2014 Variability of $\mathrm{SO}_{2}$, CO, and light hydrocarbons over a megacity in eastern India: Effects of emissions and transport; Environ. Sci. Pollut. Res. 21(14) 8692-8706.

Midya S K and Saha U 2011 Role of the rate of change of Total Column Ozone during different seasons on the prediction of Indian summer monsoon rainfall over Gangetic West Bengal, India; Ind. J. Phys. 85 1461-1468.

Midya S K, Ghosh D, Ganda S C and Sarkar H 2011 Seasonal variation of daily total column ozone (TCO) and role of its depletion and formation rate on surface temperature over Dumdum at Kolkata, India; Ind. J. Phys. 85 1247-1256.

Rex M, Salawitch R J, von der Gathen P, Harris N R P, Chipperfield M P and Naujokat B 2004 Arctic ozone loss and climate change; Geophys. Res. Lett. 31.

Seinfeld J H and Pandis S N 2006 Atmospheric chemistry and physics: From air pollution to climate change; John Wiley \& Sons.

Vanicek K, Frei T, Litynska Z and Schmalwieser A 2000 UVindex for the public; A guide for publication and interpretation of solar UV Index forecasts for the public prepared by the Working Group 4 of the COST-713 Action "UVB Forecasting"; Eur. Coop. in the Field of Sci. and Tech. Res., Brussels.

Varotsos C A, Chronopoulos G J, Katsikis S and Sakellariou N K 1995 Further evidence of the role of air pollution on solar ultraviolet radiation reaching the ground; Int. J. Remote Sens. 16 1883-1886.

World Health Organization 2002 Global Solar UV Index: A Practical Guide; Geneva, Switzerland.

Ziemke J R, Chandra S, McPeters R D and Newman P A 1997 Dynamical proxies of column ozone with applications to global trend models; J. Geophys. Res.: Atmospheres (1984-2012) 102 6117-6129. 